\title{
Staged laparotomies based on the damage control principle to treat hemodynamically unstable grade IV blunt hepatic injury in an eight-year-old girl
}

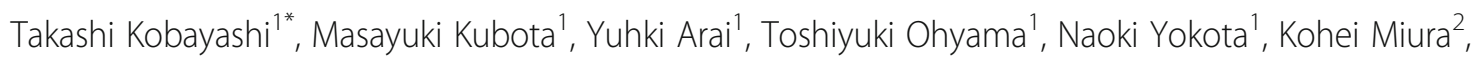
Hirosuke Ishikawa², Daiki Soma², Kazuyasu Takizawa², Jun Sakata², Masayuki Nagahashi ${ }^{2}$, Hitoshi Kameyama² and Toshifumi Wakai ${ }^{2}$

\begin{abstract}
Background: Severe blunt hepatic injury is a major cause of morbidity and mortality in pediatric patients. Damage control (DC) surgery has been reported to be useful in severely compromised children with hepatic injury. We applied such a technique in the treatment of a case of hemodynamically unstable grade IV blunt hepatic injury in an eight-year-old girl. This case is the first to use multimodal approaches including perihepatic packing, temporary closure of the abdominal wall with a plastic sheet, transarterial embolization (TAE), and planned delayed anatomical hepatic resection in a child.
\end{abstract}

Case presentation: An eight-year-old girl was run over by a motor vehicle and transferred to the emergency department of the local hospital. Her diagnoses were severe blunt hepatic injury (grade IV) with left femoral trochanteric fracture. No other organ injuries were observed. Because her hemodynamic state was stable under aggressive fluid resuscitation, she was transferred to our hospital for surgical management. On arrival at our institution about $4 \mathrm{~h}$ after the injury, her hemodynamic condition became unstable. Abdominal compartment syndrome also became apparent. Because her condition had deteriorated and the lethal triad of low BT, coagulopathy, and acidosis was observed, a DC treatment strategy was selected. First, emergent laparotomy was performed for gauze-packing hemostasis to control intractable bleeding from the liver bed, and the abdomen was temporarily closed with a plastic sheet with continuous negative pressure aspiration. Transarterial embolization of the posterior branch of the right hepatic artery was then carried out immediately after the operation. The lacerated right lobe of the liver was safely resected in a stable hemodynamic condition 2 days after the initial operation. Bleeding from the liver bed ceased without further need of hemostasis. She was transferred to the local hospital without any surgical complications on day 42 after admission. She had returned to her normal life by 3 months after the injury.

Conclusion: The DC strategy was found to be effective even in a pediatric patient with hemodynamically unstable severe blunt hepatic injury. The presence of the deadly triad (hypothermia, coagulopathy, and acidosis) and abdominal compartment syndrome was an indication for DC surgery.

Keywords: Blunt hepatic injury, Children, Damage control surgery, Transarterial embolization, Delayed hepatic resection

\footnotetext{
* Correspondence: kobataka@med.niigata-u.ac.jp

${ }^{1}$ Department of Pediatric Surgery, Niigata University Graduate School of

Medical and Dental Sciences, 1-757, Asahimachi-dori, Chu-o-ku, Niigata

951-8510, Japan

Full list of author information is available at the end of the article
} 


\section{Background}

Damage control (DC) surgery has created a paradigm shift in strategies of simultaneous definitive repair of injured organs. In DC surgery, the initial surgery is performed to control hemorrhaging and stabilize the general circulation, after which definitive surgeries are performed as needed $[1,2]$.

The application of DC principles is considered when a patient shows the lethal triad of hemorrhagic shock associated with acidosis, coagulopathy, and hypothermia. In children, the indication for DC surgery is considered to be the same as in adults. However, children are anatomically and physiologically different from adults in many respects. Therefore, the application of expeditious DC surgery is mandatory in children with exsanguinating hepatic and/or vascular injuries [3]. We herein report a case of an eight-yearold girl with right hepatic injury who was hit by an automobile. Her severe hemorrhagic shock was successfully managed by DC surgery.

To our knowledge, this case is the first using multimodal approaches including perihepatic packing, temporary closure of the abdominal wall with a plastic sheet, transarterial embolization (TAE), and planned delayed anatomical hepatic resection in a child.

\section{Case presentation}

The patient was an eight-year-old Japanese girl who lived in the northern area of Japan. A large amount of snow had piled up on the sidewalk, and while she was enjoying this snow, she accidentally slid down into the road and was run over by a motor vehicle. She was transferred to the emergency department of the local hospital about $48 \mathrm{~min}$ after the accident. On arrival, she complained of severe upper abdominal pain with prominent abdominal distention. She was pale, and a tire mark obliquely running over the right lower abdomen was found. Although her blood pressure (BP) was maintained at $109 / 71 \mathrm{mmHg}$, her heart rate (HR) was increased to $157 \mathrm{bpm}$. Her respiratory rate (RR) was $30 \mathrm{bpm}$, and the percutaneous oxygen saturation on the index finger $\left(\mathrm{SatO}_{2}\right)$ was $100 \%$. She scored a 15 on the Glasgow coma scale (GCS). Focused assessment with sonography for trauma revealed intraperitoneal fluid collection, suggesting hemoperitoneum. Her BP decreased to 77/57 mmHg soon after admission, and fluid resuscitation with $30 \mathrm{ml} / \mathrm{kg}$ lactated Ringer's solution was started. Her hemodynamic condition recovered with a BP of 109/75 $\mathrm{mmHg}$, and her HR slightly dropped to $139 \mathrm{bpm}$.

A contrast-enhanced computed tomography (CT) scan taken after she achieved hemodynamic stabilization showed a parenchymal disruption of the right hepatic lobe (grade IV) $[4,5]$ with extravasation of contrast material from the hepatic artery to the peritoneal cavity (Fig. 1a, b). Left trochanteric fracture of the femur was also observed. No other organ injuries were observed. Her initial serum hemoglobin level, platelet count, and \% prothrombin time were $10.8 \mathrm{~g} / \mathrm{dl}, 21.4 \times 10^{4} / \mu \mathrm{l}$, and $72.7 \%$ before fluid resuscitation, respectively. She was transferred to our hospital for surgical management.

During the emergent transportation by an ambulance, her hemodynamic condition was stable with fluid resuscitation and blood transfusion. Another $30 \mathrm{ml} / \mathrm{kg}$ of lactated Ringer's solution and $560 \mathrm{ml}$ of packed red blood cells (four units) were given. On arrival at our institution about $4 \mathrm{~h}$ after the injury, her hemodynamic condition became unstable. Her BP was 90/58 mmHg, HR was 126 beats per minute, and RR was 19 breaths per minute. Her body temperature (BT) was $34.6{ }^{\circ} \mathrm{C}$, and $\mathrm{SatO}_{2}$ was $100 \%$ under a $10-\mathrm{L}$ oxygen mask. Her GCS was 15 . She was pale, and her abdomen was remarkably distended. Because she was hemodynamically unstable, we added another $840 \mathrm{ml}$ of packed red blood cells (six units). Despite aggressive hemodynamic resuscitation, her vital signs were still unstable. Abdominal compartment syndrome became apparent. At this time, her serum hemoglobin was $15.9 \mathrm{~g} / \mathrm{dl}$, and the platelet count was $1.7 \times 10^{4} / \mu$ l. The coagulation panel of the prothrombin time international normalized ratio was abnormal at 2.78 , and her fibrinogen level had decreased to $34 \mathrm{mg} / \mathrm{dl}$. Her acidosis progressed to a $\mathrm{pH}$ of $7.131, \mathrm{HCO}_{3}^{-}$of $13.6 \mathrm{mmol} / \mathrm{l}, \mathrm{BE}$ of $-15.08 \mathrm{mmol} / \mathrm{l}$, and lactate of $7.2 \mathrm{mmol} / \mathrm{l}$. Moderate transaminitis with aspartate aminotransferase of $223 \mathrm{U} / \mathrm{l}$ and alanine aminotransferase of 163 $\mathrm{U} / \mathrm{l}$ were also found. The total bilirubin level was $0.5 \mathrm{mg} /$ $\mathrm{dl}$, and the alkaline phosphatase level was $193 \mathrm{U} / \mathrm{l}$.

Because her condition had deteriorated and the lethal triad of low BT, coagulopathy, and acidosis was observed, a DC treatment strategy was selected. We planned to perform perihepatic gauze packing first and then immediately perform TAE with interventional radiology. After rapid intubation in the emergency room, she was transferred to the operating room. A 7-Fr intraaortic balloon occlusion catheter was inserted via the left femoral artery before opening the abdomen to stabilize the general circulation. The liver was ruptured and a deep laceration was observed between the right anterior and the right lateral section of the liver after opening the abdomen. The posterior branch of the portal vein and the right hepatic artery was injured. The right hepatic vein was also injured and bleeding severely. We performed perihepatic gauze packing using Pringle's maneuver with intermittent inflation of the intra-aortic balloon to maintain adequate blood pressure. The venous bleeding was controlled by direct surgical gauze packing, but the arterial bleeding continued. We placed drainage tubes into the abdominal cavity. Since the intestine was edematous and distended, primary closure of the 

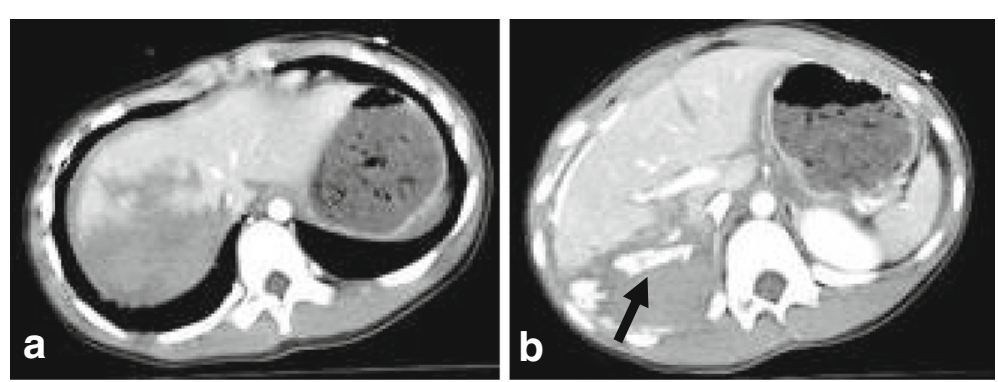

Fig. 1 a, b Axial view of an enhanced abdominal computed tomography (CT) scan shows the presence of active extravasation (arrow), large devascularization of the right hepatic lobe, and hemoperitoneum

abdominal wall was impossible. We therefore covered the abdomen using a plastic sheet (Fig. 2). The operative time was $91 \mathrm{~min}$, total blood loss was $1500 \mathrm{ml}$, and the total blood transfused during the operation was $560 \mathrm{ml}$ of red blood cells (four units), $960 \mathrm{ml}$ of freshly frozen plasma (eight units), and $400 \mathrm{ml}$ of platelets (ten units $\times 2$ ).

Immediately after perihepatic packing, she was transferred to the interventional radiology suite for diagnosis and treatment (about $8 \mathrm{~h}$ after injury). Acidosis (pH 7.238), coagulopathy (\% prothrombin time 18\%), and low BT $\left(34.0{ }^{\circ} \mathrm{C}\right)$ were still observed. The radiologists were ready to perform TAE. A 5-Fr vascular catheter was inserted via the right femoral artery. Superior mesenteric arteriography revealed poor right portal venous flow. Celiac arteriography revealed extravasation from a posterior branch of the right hepatic artery (Fig. 3a). The posterior segmental branch was successfully embolized with gelatin sponge particles and nine hypersoft detachable helical coils (Fig. 3b). Complete arterial hemostasis was achieved and confirmed by hepatic arteriography. The TAE procedure time was $125 \mathrm{~min}$. A

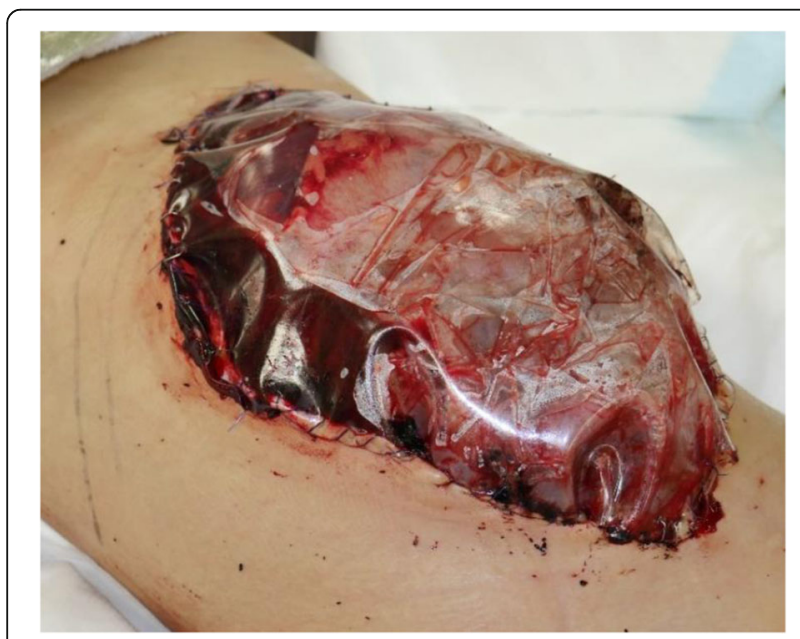

Fig. 2 The patient's abdomen after damage control surgery. Venous hemostasis was achieved by direct surgical gauze packing, and then the abdomen was closed temporarily using a plastic sheet to cover it total of $720 \mathrm{ml}$ of freshly frozen plasma (six units) and $200 \mathrm{ml}$ of platelets (ten units) was given during TAE.

The patient was transferred to the intensive care unit (ICU). In order to stabilize her hemodynamic condition, she was treated with re-warming, intravenous fluids, and bed rest. On admission to ICU, her BP was 120/78 $\mathrm{mmHg}$, HR was $132 \mathrm{bpm}$. Acidosis (pH 7.257), coagulopathy (\% prothrombin time $34 \%$ ), and low BT $\left(35.9{ }^{\circ} \mathrm{C}\right)$ were still observed. Serial hemoglobin measurements revealed no reduction in the hemoglobin level. Her hemodynamic state was stabilized gradually. Her $\mathrm{pH}$ was 7.418 , \% prothrombin time was $51 \%$, and BT was $38.5^{\circ} \mathrm{C}$ at $48 \mathrm{~h}$ after medical treatment in ICU. Acidosis, coagulopathy, and low BT were all improved. At $48 \mathrm{~h}$ after perihepatic packing and TAE, we decided to perform re-laparotomy and delayed hepatic resection. There was two reasons to perform second operation. The first reason was the necessity of removal of the packed gauze and the closure of the abdomen to avoid infectious complications. The second reason was hepatic necrosis after TAE. Hepatic necrosis is high risk of hepatic abscesses. In our institute, hepatic necrosis is the indication of hepatectomy for successfully bleeding arrested cases after damage control surgery. We confirmed no portal flow of the posterior branch by the doppler ultrasonography before second operation. We gently removed the gauze for perihepatic packing and irrigated the abdominal cavity. We carefully confirmed hemostasis of the liver and the presence of necrotic lesions in the segments VI and VII. We performed extended right lateral sectionectomy including the necrotic area and laceration of the liver using Pringle's maneuver (Fig. 4a, b). The histopathological examination of the liver specimen showed the massive necrosis of the liver. The intestinal edema and distention were improved. Those findings allowed us to perform direct closure of the abdominal wall. The total ischemic time of the whole liver was $30 \mathrm{~min}$, the operative time was $251 \mathrm{~min}$, the total blood loss was $240 \mathrm{ml}$, and the intraoperative blood transfusion was $280 \mathrm{ml}$ of red blood cells (two units) and $240 \mathrm{ml}$ of fresh frozen plasma (two units). 

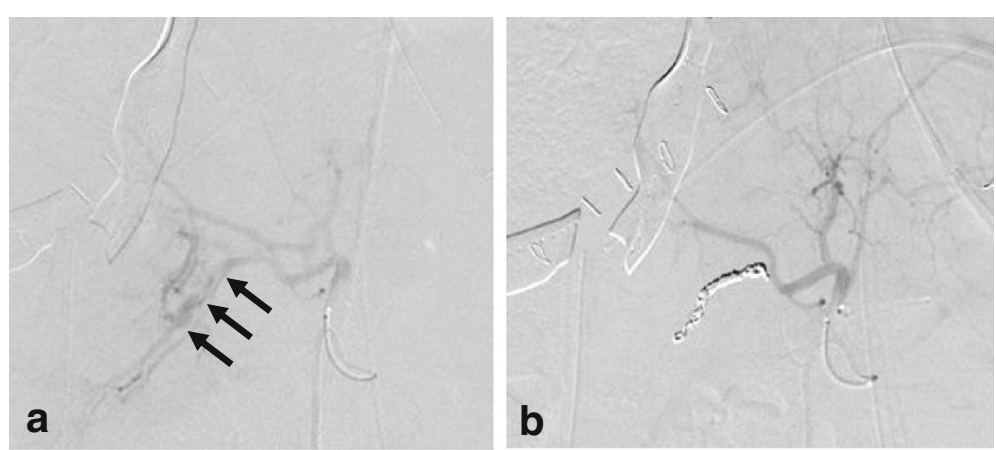

Fig. 3 a Hepatic angiography immediately after perihepatic packing shows extravasation arising from a posterior branch (arrows) of the right hepatic artery. $\mathbf{b}$ Hepatic angiography after coil embolization shows the complete cessation of extravasation and a preserved patency of the anterior branch of the right hepatic artery

The patient was returned to the ICU and received intensive care. Her postoperative course was uneventful. Her left trochanteric fracture was surgically treated with open reduction and internal fixation on day 5 after admission. Her total ICU stay was 10 days. A follow-up abdominal CT scan with contrast showed sufficient portal and hepatic arterial flow without extravasation, abscess formation, or biloma on day 14 (Fig. 5) and day 28 after the delayed hepatic resection. She was transferred to the local hospital to continue physical rehabilitation on day 42 after admission. She was discharged from the local hospital and went home on day 69 after the onset of her blunt liver injury. She had returned to her normal life by 3 months after the injury.

\section{Discussion}

Abdominal trauma is a frequent cause of morbidity and mortality in children. Liver injury occurs in $15-20 \%$ of all pediatric patients with abdominal trauma [6]. The management of pediatric liver injuries has evolved over the last three decades [7], with decreasing rates of operative intervention. Currently, nonoperative management is considered to be the standard care in children suffering from blunt solid organ injury who are in a hemodynamically stable condition, with success rates exceeding 90\% [8]. However, pediatric patients in hemodynamically unstable conditions due to blunt solid organ injury are considered candidates for operative intervention. In such critical situations, the DC strategy has proven useful for life-saving maneuvers.

The principles of DC in children are the same as in adults. Damage control was reported by the group at the University of Pennsylvania in 1993 [9]. They described the initial control of hemorrhaging by gauze packing and decontamination by saline irrigation of the abdominal cavity. After temporal closure of the abdominal wall with a plastic sheet, further intensive care should be done in the ICU, and delayed definitive repair of intraabdominal injuries should be performed. A rapid transfusion of a large volume of resuscitation fluid to maintain stable vital signs with massive hemorrhaging results in coagulopathy, known as the bloody vicious cycle. This is statistically correlated with hypothermia and acidosis, and the three signs of coagulopathy, hypothermia, and acidosis constitute the deadly triad [10]. In the present case, the patient showed hemorrhagic shock with hypothermia, acidosis, and coagulopathy. She was also diagnosed with abdominal compartment syndrome due to massive intra-

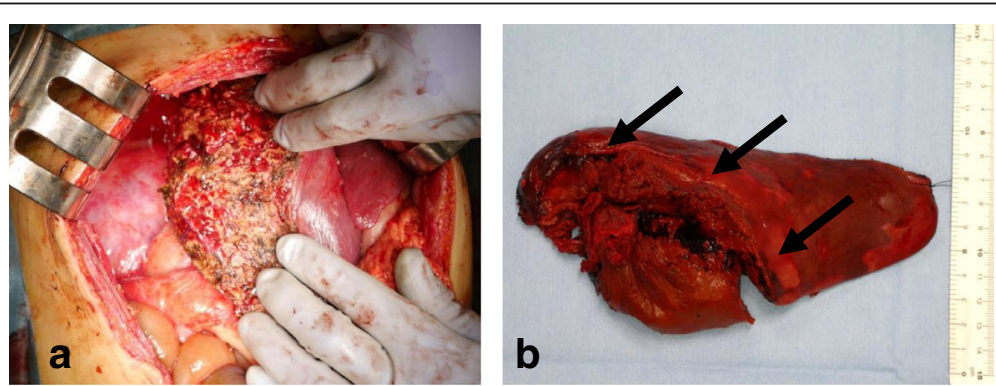

Fig. 4 a Operative view immediately after delayed hepatectomy. Extended right lateral sectionectomy was performed after 48 hours of perihepatic packing. $\mathbf{b}$ A surgical specimen of the delayed hepatectomy. The excised liver was completely necrotic macroscopically and deep liver laceration was observed (arrows) 


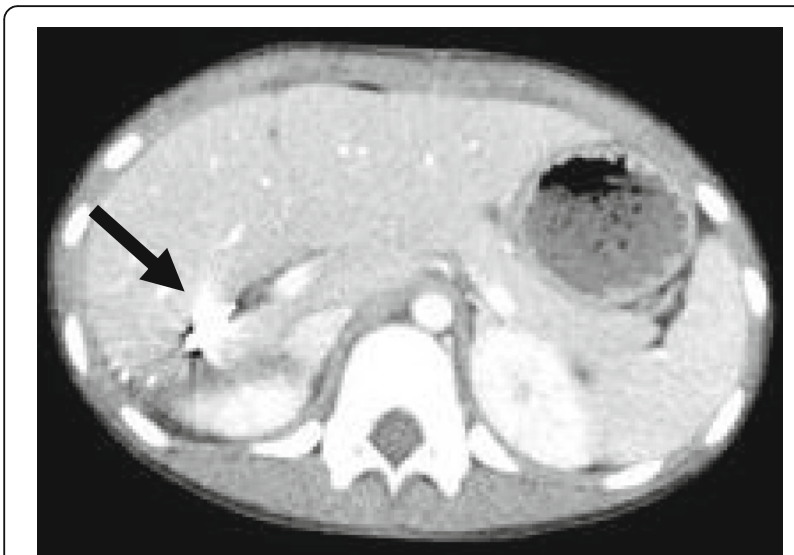

Fig. 5 An axial view of an enhanced abdominal computed tomography $(\mathrm{CT})$ scan on the 14th day after extended right lateral sectionectomy shows no evidence of an intra-abdominal abscess and biloma. Embolized coils (arrow) are also observed

abdominal fluid collection. For these reasons, we adopted a DC strategy.

Temporary gauze packing in DC surgery has been reported to be useful in pediatric patients [11]. Stylianos reported 22 children 6 days to 20 years of age in whom intractable bleeding from the liver was controlled by gauze packing, and $90 \%$ of these cases were associated with coagulopathy, hypothermia, and acidosis. Packing was reported to be useful for controlling hemorrhaging in $95 \%$ of the patients. Temporal abdominal closure was required in $45 \%$ of the patients, and $82 \%$ of the patients survived [11]. We also selected temporal abdominal wall closure with a plastic sheet in the present case, because the edematous intestine was markedly dilated.

TAE of hepatic arterial injuries has been used for hemodynamically stable adult patients as an adjunct procedure of nonoperative management. TAE has also been recommended as a treatment for bleeding after DC surgery [12]. This procedure is currently widely accepted, and the success rate has been reported to be $83-100 \%$ [13-15]. In children, only a few cases of TAE for blunt hepatic injury have been reported, all of whom are still alive at the time of filing $[6,16-22]$. In a review of TAE used in hemodynamically stable trauma pediatric cases, the complication rates ranged from 0 to $4 \%$ and were mostly minor troubles such as puncture site hematoma [16]. In the present case, the application of TAE after gauze packing hemostasis of venous bleeding appeared to be effective for controlling arterial bleeding from the injured liver. Although the patient developed hepatic necrosis after TAE, this complication was expected and is a common complication after TAE in adults, especially with high-grade liver injury. Dabbs et al. reported that $42.2 \%$ of patients went on to develop a major hepatic necrosis after TAE, and $96.7 \%$ of patients with a major hepatic necrosis needed operative intervention [23]. In our institute, hepatic necrosis is the indication of hepatectomy for successfully bleeding arrested cases after DC surgery. Delayed hepatic resection for the necrotic injured liver after DC surgery and TAE is well established in adults [24]. However, there have been no reports of pediatric cases. Li Petri et al. reported their excellent results suggesting that delayed hepatic resection may be an option in select cases at institutions with the appropriate expertise [24]. In the present case, TAE of the selected artery proved useful for reducing the area of liver necrosis and minimizing the operative insult of liver resection. Delayed hepatic resection was accomplished safely without any complications.

\section{Conclusions}

The DC strategy was found to be effective even in a pediatric patient with hemodynamically unstable severe blunt hepatic injury. The presence of the deadly triad (hypothermia, coagulopathy, and acidosis) and abdominal compartment syndrome was an indication for this patient to undergo DC surgery. A correct and early decision regarding surgery is necessary to achieve a good outcome. Collaborative teamwork with emergency physicians, anesthesiologists, interventional radiologists, and liver surgeons will further improve the usefulness of DC surgery.

\section{Abbreviations}

BP: Blood pressure; BT: Body temperature; $\mathrm{CT}$ : Computed tomography; DC: Damage control; GCS: Glasgow coma scale; HR: Heart rate; ICU: Intensive care unit; RR: Respiratory rate; $\mathrm{SatO}_{2}$ : Percutaneous oxygen saturation on the index finger; TAE: Transarterial embolization

\section{Acknowledgements}

We thank Brian Quinn who provided English editing services on behalf of Japan Medical Communication Ltd.

\section{Funding}

No funding was received for this study.

\section{Authors' contributions}

TK, YA, TO, and NY drafted the manuscript. KM, HI, DS, KT, JS, MN, and HK carried out the acquisition of data. MK, and TW participated in the critical revision of the manuscript. All authors read and approved the final manuscript.

\section{Competing interests}

The authors declare that they have no competing interests.

\section{Consent for publication}

Written informed consent was obtained from the patient's parent for publication of this case report and any accompanying images. A copy of the written consent is available for review by the Editor-in-Chief of this journal.

\section{Author details}

${ }^{1}$ Department of Pediatric Surgery, Niigata University Graduate School of Medical and Dental Sciences, 1-757, Asahimachi-dori, Chu-o-ku, Niigata 951-8510, Japan. ${ }^{2}$ Division of Digestive and General Surgery, Niigata University Graduate School of Medical and Dental Sciences, Niigata, Japan.

Received: 16 June 2016 Accepted: 10 November 2016

Published online: 16 November 2016 


\section{References}

1. Piper GL, Peitzman AB. Current management of hepatic trauma. Surg Clin North Am. 2010;90:775-85.

2. Rotondo MF, Zonies $\mathrm{DH}$. The damage control sequence and underlying logic. Surg Clin North Am. 1997;77:761-77.

3. Hamill J. Damage control surgery in children. Injury. 2004;35:708-12.

4. Moore EE, Shackford SR, Pachter HL, McAninch JW, Browner BD, Champion HR, Flint LM, Gennarelli TA, Malangoni MA, Ramenofsky ML, et al. Organ injury scaling: spleen, liver, and kidney. J Trauma. 1989;29:1664-6.

5. Moore EE, Cogbill TH, Jurkovich GJ, Shackford SR, Malangoni MA, Champion HR. Organ injury scaling: spleen and liver (1994 revision). J Trauma. 1995;38: 323-4.

6. Ohtsuka Y, Iwasaki K, Okazumi S, Yoshida H, Matsunaga T, Kouchi K, Okada T, Ohnuma N. Management of blunt hepatic injury in children: usefulness of emergency transcatheter arterial embolization. Pediatr Surg Int. 2003;19:29-34.

7. Gaines BA. Intra-Abdominal solid organ injury in children: diagnosis and treatment. J Trauma. 2009;67:S135-S9.

8. Giss SR, Dobrilovic N, Brown RL, Garcia VF. Complications of nonoperative management of pediatric blunt hepatic injury: diagnosis, management, and outcomes. J Trauma. 2006;61:334-9.

9. Rotondo MF, Schwab CW, McGonigal MD, Phillips 3rd GR, Fruchterman TM, Kauder DR, Latenser BA, Angood PA. 'Damage control': an approach for improved survival in exsanguinating penetrating abdominal injury. J Trauma. 1993:35:375-82. discussion 82-3.

10. Cosgriff N, Moore EE, Sauaia A, Kenny-Moynihan M, Burch JM, Galloway B. Predicting life-threatening coagulopathy in the massively transfused trauma patient: hypothermia and acidoses revisited. J Trauma. 1997;42:857-61. discussion 61-2.

11. Stylianos S. Abdominal packing for severe hemorrhage. J Pediatr Surg. 1998; 33:339-42.

12. Misselbeck TS, Teicher EJ, Cipolle MD, Pasquale MD, Shah KT, Dangleben DA, Badellino MM. Hepatic angioembolization in trauma patients: indications and complications. J Trauma. 2009:67:769-73.

13. Hagiwara A, Yukioka T, Ohta S, Tokunaga T, Matsuda H, Shimazaki S. Nonsurgical management of patients with blunt hepatic injury: efficacy of transcatheter arterial embolization. AJR Am J Roentgenol. 1997;169:1151-6.

14. Wahl WL, Ahrns KS, Brandt MM, Franklin GA, Taheri PA. The need for early angiographic embolization in blunt liver injuries. J Trauma. 2002:52:1097-101.

15. Letoublon C, Morra I, Chen Y, Monnin V, Voirin D, Arvieux C. Hepatic arterial embolization in the management of blunt hepatic trauma: indications and complications. J Trauma. 2011;70:1032-6. discussion 6-7.

16. Puapong D, Brown CV, Katz M, Kasotakis G, Applebaum H, Salim A, Rhee P, Demetriades D. Angiography and the pediatric trauma patient: a 10-year review. J Pediatr Surg. 2006:41:1859-63.

17. Monnin V, Sengel C, Thony F, Bricault I, Voirin D, Letoublon C, Broux C, Ferretti G. Place of arterial embolization in severe blunt hepatic trauma: a multidisciplinary approach. Cardiovasc Intervent Radiol. 2008;31:875-82.

18. Kiankhooy A, Sartorelli KH, Vane DW, Bhave AD. Angiographic embolization is safe and effective therapy for blunt abdominal solid organ injury in children. J Trauma. 2010;68:526-31.

19. Lin BC, Wong YC, Lim KE, Fang JF, Hsu YP, Kang SC. Management of ongoing arterial haemorrhage after damage control laparotomy: optimal timing and efficacy of transarterial embolisation. Injury. 2010;41:44-9.

20. Ong CC, Toh L, Lo RH, Yap TL, Narasimhan K. Primary hepatic artery embolization in pediatric blunt hepatic trauma. J Pediatr Surg. 2012;47: 2316-20.

21. Fallon SC, Coker MT, Hernandez JA, Pimpalwar SA, Minifee PK, Fishman DS, Nuchtern JG, Naik-Mathuria BJ. Traumatic hepatic artery laceration managed by transarterial embolization in a pediatric patient. J Pediatr Surg. 2013:48:E9-12

22. Lin BC, Fang JF, Chen RJ, Wong YC, Hsu YP. Surgical management and outcome of blunt major liver injuries: experience of damage control laparotomy with perihepatic packing in one trauma centre. Injury. 2014;45:122-7.

23. Dabbs DN, Stein DM, Scalea TM. Major hepatic necrosis: a common complication after angioembolization for treatment of high-grade liver injuries. J Trauma. 2009;66:621-7. discussion 7-9.

24. Li Petri S, Gruttadauria S, Pagano D, Echeverri GJ, Di Francesco F, Cintorino D, Spada M, Gridelli B. Surgical management of complex liver trauma: a single liver transplant center experience. Am Surg. 2012;78:20-5.

\section{Submit your manuscript to a SpringerOpen ${ }^{\circ}$ journal and benefit from:}

- Convenient online submission

- Rigorous peer review

- Immediate publication on acceptance

Open access: articles freely available online

- High visibility within the field

- Retaining the copyright to your article 